\title{
Vibration Frequency Characteristic Study of Two-stage Excitation Valve Used in Vibration Experiment System
}

\author{
Yongping $\mathrm{WU}^{1}$, Chengwei XIONG ${ }^{1}$, Yi LIU $^{1 *, 2}$, Jiafei ZHENG ${ }^{1}$, Mingxuan $\mathrm{ZOU}^{1}$
}

1 NingboTech University, Ningbo 315100, China

2 Ningbo Shenglong Automotive Powertrain Systems Co., Ltd Ningbo 315105, China

*Corresponding Author: Yi LIU, NingboTech University, Qianhu South Road No. 1, Ningbo 315100, Zhejiang Province, China; liuyilulu@ nit.zju.edu.cn

\begin{abstract}
:
To satisfy the demands of higher frequency and amplitude in hydraulic vibration experiment system, the two-stage excitation valve is presented, and a mathematical model of two-stage excitation valve is established after analyzing the working principle of two-stage excitation valve, then the influence of relevant parameters on the displacement of main spool of two-stage excitation valve is studied by using Matlab/Simulink to calculate and analyze. The results show that the displacement of main spool will be smaller with bigger diameter and more secondary valve ports. When the reversing frequency is higher and the oil supply pressure is lower as well as the axial guide width of valve ports is smaller, the maximum displacement of main spool is smaller. The new two-stage excitation valve is easy to adjust reversing frequency and flow. The high frequency can be achieved by improving the rotation speed of servo motor and adding the number of secondary valve ports; the large flow can be realized by increasing the axial guide width of secondary valve ports and oil supply pressure. The result of this study is of guiding significance for designing the rotary valve for the achievement of higher reversing frequency and larger flow.

Keywords: two-stage excitation valve; rotary valve control; mathematical modelling; numerical analysis
\end{abstract}

\section{Introduction}

Vibration equipment mainly refers to a kind of equipment to generate corresponding vibration. With the further research on high-frequency electro-hydraulic vibration equipment, the vibration frequency has been greatly improved in recent years ${ }^{[1]}$. Due to the limitation of system frequency bandwidth and the influence of nonlinearity, the traditional electro-hydraulic vibration control technology based on servo control has a deviation between the response signal and the expected input signal, which is difficult to meet the current high accuracy and large flow ${ }^{[2,3]}$. Hydraulic rotary valve is used to control oil circuit's on-off and direction based on the spool's rotation relative to the valve sleeve or valve body. Compared with hydraulic slide valve, hydraulic rotary valve is significantly different on structural features and performance parameters. So far, the researches on rotary valve are as follows: Ivan Okhotnikov et al. investigated the metering characteristic and pressure losses of the rotary tubular spool valve $\mathrm{e}^{[4]}$. Hao Jiangong et al. improved the vibration frequency and the flow of wave generator through the structure of rotary valve, and applied it to the mining industry, metallurgical industry, construction industry and so on ${ }^{[5]}$. Lu Juxian et al. designed a servo rotary valve and $\mathrm{Fu}$ Yongling et al. analyzed the structure and principle of its rotary spool, then deduced the steady flow force when it was working and did a simulating calculation $^{[6,7]}$. Ren Yan et al. presented various series rotary valves applied in the field of vibration engineer and studied the frequency characteristic of electrohydraulic vibration excitor controlled by rotary valve ${ }^{[8-10]}$. Gong Guofang proposed a high speed rotary valve with fourway commutation that can improve the frequency and flow, which applied to the high-power variable-frequency vibration of tamping device ${ }^{[11]}$. Li Xing et al. developed the spool transferring composite hydraulic vibration control valve and its hydraulic system ${ }^{[12]}$. Cui Jian developed a direct-acting electrohydraulic rotary valve ${ }^{[13]}$. Liu Yi et

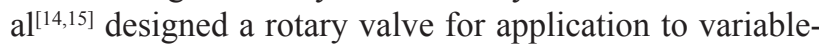
frequency vibration condition. The rotary valve can be used to obtain the required vibration frequency and waveform, and thus meet different working requirements of the tamping machine and wave maker.

In this paper, in order to further increase the reversing 
frequency and the flow of rotary valve in hydraulic vibration experiment system, a new two-stage excitation valve element is presented based on the analysis of the application of the above rotary valve control elements. Then the working principle of two-stage excitation valve is described and the mathematical model is established. Finally, the characteristic of two-stage excitation valve is numerically analyzed.

\section{Working Principle of Two-stage Excitation Valve}

The working principle of two-stage excitation valve is shown in Fig. 1. the oil ports of main valve communicate with the corresponding oil ports of secondary rotary valve. The stepping motor makes secondary spool moving, so the opening size of spool can be changed, and then control the flow of oil. The servo motor drives the secondary spool rotation. Because of the multiple symmetric arrangement ports in four steps of secondary spool, when secondary spool cycles one revolution, the oil reverse several times. The rotation and movement of secondary spool are driven by the control electromotor when the oil flow from the intake of main valve into the intake of secondary valve, so that the oil of secondary valve can communicate with the oil of the right and left chambers of main spool, and then the main spool can move around. Finally, the oil of main valve is inverted. As shown in Fig.1, the oil-way of secondary valve as indicated by the arrows, the oil that flow into the control chamber of main spool can be directed to right end so that the main spool move left to make $\mathrm{P}$ switch on B and A switch on T. The control oil will flow into the left side of main spool control chamber when the secondary spool continue to rotate to an angle, then the main spool will move right to make $\mathrm{P}$ switch on $\mathrm{A}$ and $\mathrm{B}$ switch on $\mathrm{T}$.

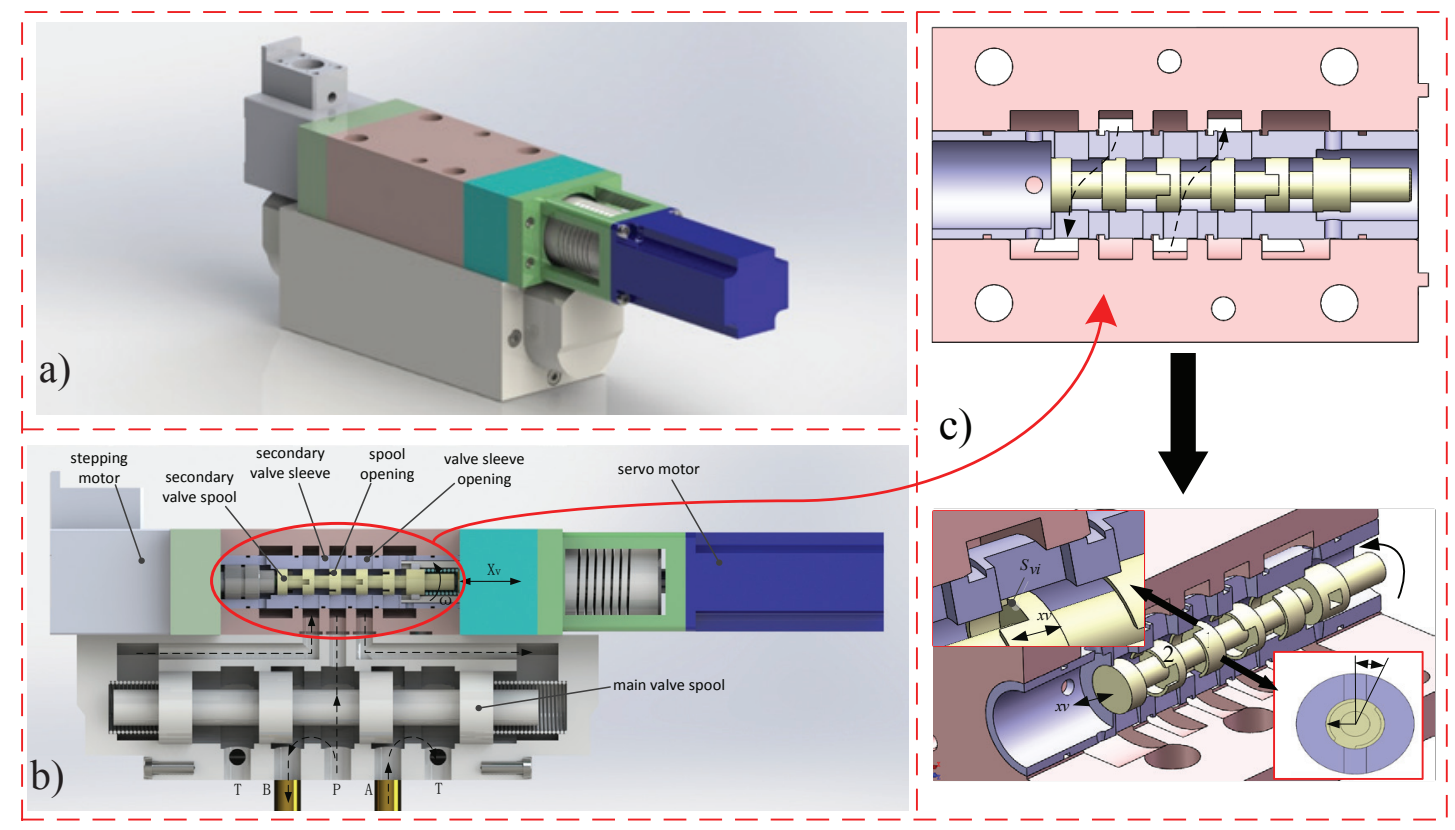

(a) Overall chart. (b) Structural schematic diagram. (c) Reversing schematic diagram.

Figure 1 Two-stage excitation valve

\section{Mathematical Modelling}

According to the working principle diagram, the equivalence principle analysis diagram is shown in Fig. 2.

The top part of diagram is the simplified model of secondary rotary valve, shown in Fig. 1(c).

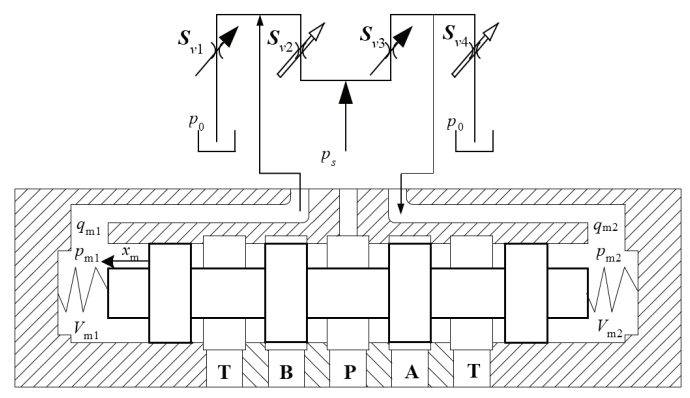

Figure 2 Equivalence principle analysis diagram

\subsection{Flow equation of secondary rotary valve}

It is assumed that the flow is the ideal fluid in the steady condition, the oil-supply pressure $p_{\mathrm{s}}$ is constant, $p_{0}$ is the return pressure of hydraulic system, $q_{\mathrm{s}}$ is the supply flow, the pressure of hydraulic cylinder two chambers are $p_{\mathrm{ml}}$ and $p_{\mathrm{m} 2}$, respectively, $S_{\mathrm{vi}}$ is the conduction area of rotary valve port. On the basis of orifice flow equation in the hydrodynamics theory, the equation of the flow through orifices 1, 2, 3, and 4 are shown as follows:

$q_{v 1}=C_{d} S_{v}\left(x_{v}, t\right) \sqrt{\frac{2\left(p_{\mathrm{m} 1}-p_{0}\right)}{\rho}}$
$q_{v 2}=C_{d} S_{v}\left(x_{v}, t\right) \sqrt{\frac{2\left(p_{s}-p_{\mathrm{m} 1}\right)}{\rho}}$
$q_{v 3}=C_{d} S_{v}\left(x_{v}, t\right) \sqrt{\frac{2\left(p_{s}-p_{\mathrm{m} 2}\right)}{\rho}}$ 
$q_{v 4}=C_{d} S_{v}\left(x_{v}, t\right) \sqrt{\frac{2\left(p_{\mathrm{m} 2}-p_{0}\right)}{\rho}}$

Where $C_{\mathrm{d}}$ is the flow coefficient, $\rho$ is the oil density.

The structure of valve is shown in Fig. $3, x_{v}$ is the axial conduction width of valve port, $R$ is the shoulder radius of the rotary spool. Assuming that every shoulder evenly open $2 n$ grooves (then in the Fig. 3 is 2), and the opening of grooves on the front and back shoulders distribute with uniformity and symmetry, the windows and grooves of valve are designed as rectangle, then the equation of the flow conduction area is $S_{v}\left(x_{v}, t\right)=2 n x_{v} y_{v}$ Assuming that the opening circumferential conduction width of front and back shoulders are $y_{v 1}$ and $y_{v 2}$, respectively, definite $y_{v 1}$ from zero to maximum, after that from maximum to zero, then enter the next opening mouth of back shoulder $y_{v 2}$, which is as well from zero to maximum, then from maximum to zero. Suppose, the rotary frequency of spool is $f$, the rotational angular velocity is $\omega_{1}$, so the equation of $y_{v 1}$ and $y_{v 2}$ are:

$$
\begin{aligned}
& y_{v 1}=\left\{\begin{array}{lc}
2 R \sin \frac{\omega_{1} t}{2} & \left(0 \leq \omega_{1} t<\frac{\pi}{4 n}\right) \\
2 R \sin \left[\frac{\pi}{4 n}-\frac{\omega_{1} t}{2}\right] & \left(\frac{\pi}{4 n} \leq \omega_{1} t<\frac{\pi}{2 n}\right) \\
0 & \left(\frac{\pi}{2 n} \leq \omega_{1} t<\frac{3 \pi}{4 n}\right) \\
0 & \left(\frac{3 \pi}{4 n} \leq \omega_{1} t \leq \frac{\pi}{n}\right)
\end{array}\right. \\
& y_{v 2}= \begin{cases}0 & \left(0 \leq \omega_{1} t<\frac{\pi}{4 n}\right) \\
0 & \left(\frac{\pi}{4 n} \leq \omega_{1} t<\frac{\pi}{2 n}\right) \\
2 R \sin \left[\frac{\omega_{1} t}{2}-\frac{\pi}{4 n}\right] & \left(\frac{\pi}{2 n} \leq \omega_{1} t<\frac{3 \pi}{4 n}\right) \\
2 R \sin \left[\frac{\pi}{2 n}-\frac{\omega_{1} t}{2}\right] & \left(\frac{3 \pi}{4 n} \leq \omega_{1} t<\frac{\pi}{n}\right)\end{cases}
\end{aligned}
$$

Fig. 3 suggests that a single complete cycle of spool valve rotation, the four times of oil reversing, so the relation of working frequency of main valve to rotational frequency of spool is $f_{m}=2 \mathrm{n} f$.

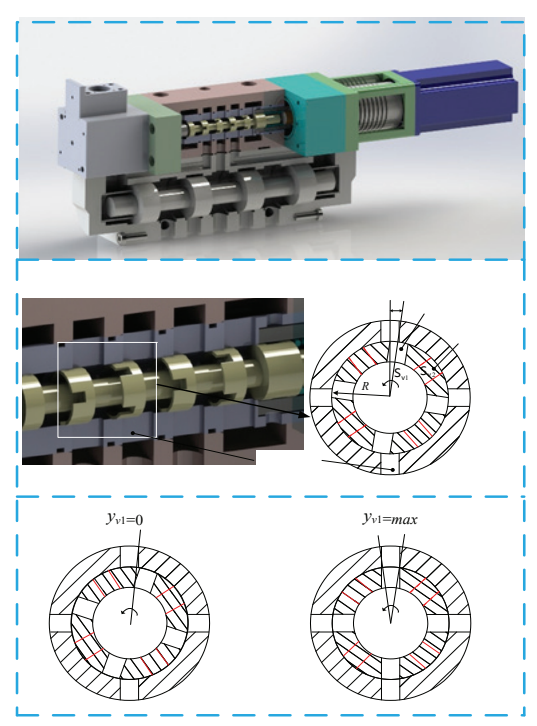

Figure 3 Structure of valve
3.2 Flow continuity equation of the right and left control chambers of main spool

For the left chamber:

$$
q \mathrm{~m} 1=q \mathrm{v} 2-q \mathrm{v} 1=A m \ddot{x}_{m}+\frac{V \mathrm{~m} 1}{E} \dot{P}_{\mathrm{m} 1}+C \varepsilon \mathrm{m} P \mathrm{~m} 1
$$

For the right chamber:

$$
q \mathrm{~m} 2=q \mathrm{v} 3-q \mathrm{v} 4=A m \ddot{x}_{m}-\frac{V \mathrm{~m} 2}{E} \dot{P}_{\mathrm{m} 2}+C \varepsilon \mathrm{mp} P \mathrm{~m} 2
$$

Where $x_{\mathrm{m}}$ is the displacement of main spool; $E$ is the bulk modulus of oil; $A_{\mathrm{m}}$ is the effective action area of main spool; $C_{\varepsilon m p}$ is the out leakage coefficient of main valve, $V_{\mathrm{m} 1}$ is the volume of main valve left chamber, $V_{\mathrm{m} 2}$ is the volume of main valve right chamber. Assuming that the initial position of spool is in the middle, then $V_{\mathrm{m} 1}=V_{\mathrm{m} 2}$.

\subsection{Force balance equation of main spool}

$A_{m}\left(P_{\mathrm{m} 1}-P_{\mathrm{m} 2}\right)=m_{m} \ddot{x}_{m}+B_{m} \dot{x}_{m}+k_{m} x_{m}+F_{m}$

Where $P_{m 1}, P_{m 2}$ are the pressure of the left and right control chamber of spool, respectively;

$m_{\mathrm{m}}$ is the mass of main spool; $x_{\mathrm{m}}$ is the displacement of main spool; $B_{\mathrm{m}}$ is the viscous damping coefficient of main spool; $k_{\mathrm{m}}$ is the spring stiffness of main spool; $F_{\mathrm{m}}$ is the steady flow force of main valve. Assuming that the motion of main spool mainly overcome the force of spring stiffness, the friction between main spool and valve sleeve is very small, about $500 \mathrm{~N}$ 's/M, the flow force is far less than the force to overcome the spring stiffness.

\section{Numerical Analysis}

According to the mathematical modelling in the sections above, the solving model of two-stage excitation valve is established through Matlab/Simulink. The total model of two-stage excitation valve can be obtained through deriving the relationship between input and output after checking the accuracy of the solving model of every subsystem, as is shown in Fig. 4. By setting every parameter of model, input different size of controlling parameters to obtain the influence on the performance of the two-stage excitation valve. The key parameters of the rotary valve are shown in Table 1.

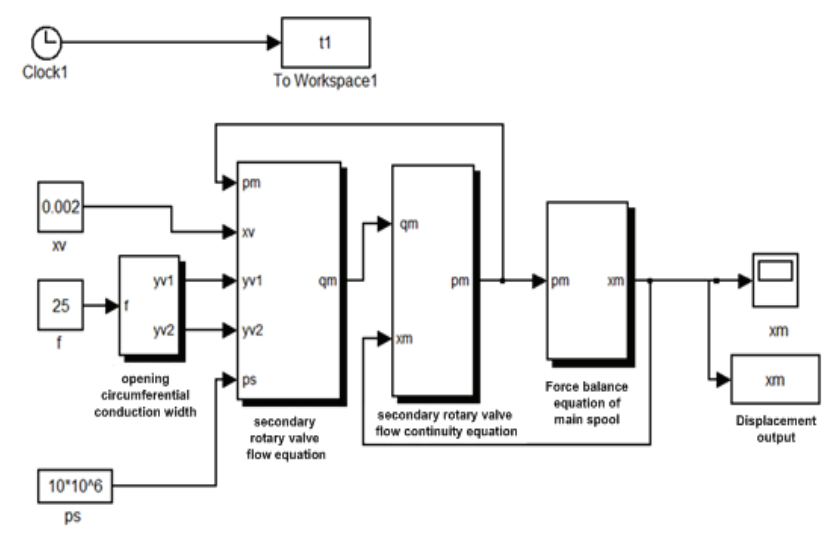

Figure 4 Solving Model of two-stage excitation valve 
Table 1 Main parameters of the system of two-stage excitation valve

\begin{tabular}{|c|c|c|c|}
\hline Parameter & Values & Parameter & Values \\
\hline$B_{\mathrm{m}}(N \cdot s / M)$ & 500 & $\mathrm{n}$ & $1-4$ \\
\hline$C_{\mathrm{d}}$ & 0.62 & $p_{\mathrm{s}}(\mathrm{Mpa})$ & $10-21$ \\
\hline$D_{\mathrm{m}}(\mathrm{mm})$ & $35-44$ & $R(\mathrm{~mm})$ & 8 \\
\hline$E(\mathrm{~Pa})$ & $8 \times 10^{8}$ & $\begin{array}{c}V_{\mathrm{m} 1}\left(\mathrm{~m}^{3}\right) \\
V_{\mathrm{m} 2}\left(\mathrm{~m}^{3}\right)\end{array}$ & $1.9 \times 10^{-5}$ \\
\hline$k_{\mathrm{m}}(\mathrm{N} / \mathrm{m})$ & 50000 & $x_{\mathrm{v}}(\mathrm{mm})$ & $1-2$ \\
\hline$m_{\mathrm{m}}(\mathrm{kg})$ & 0.5 & $y_{\mathrm{vmax}}(\mathrm{mm})$ & 3 \\
\hline$\rho\left(\mathrm{kg} / \mathrm{m}^{3}\right)$ & 870 & & \\
\hline
\end{tabular}

4.1 Influence of different main spool diameter on the displacement of main spool

Fig. 5 and 6 show the displacement of main spool and the flow area curves from different frequency when the main spool are $35 \mathrm{~mm}$ and $44 \mathrm{~mm}$, respectively. When the oil-supply pressure is $10 \mathrm{MPa}, x_{\mathrm{v}}=2 \mathrm{~mm}, D_{\mathrm{m}}=35 \mathrm{~mm}$, the

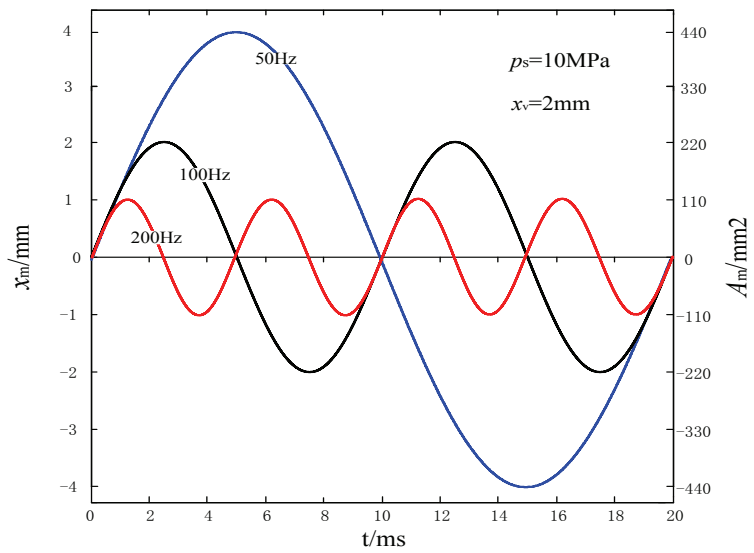

Figure 5 Curves of $x_{m}$ and $A_{m}$ with different frequency (the main spool $\mathrm{D}_{\mathrm{m}}$ is $35 \mathrm{~mm}$ )

4.2. Influence of different oil-supply pressure on the displacement of main spool

Fig.7 shows maximum value of $x_{\mathrm{m}}$ with different frequency under three different oil-supply pressure, when the reserving frequency is higher, the maximum value of $x_{\mathrm{m}}$ is smaller; when the oil-supply pressure is higher, the maximum value of $x_{\mathrm{m}}$ is bigger. When the oil-supply pressure is $21 \mathrm{MPa}, x_{\mathrm{v}}=2 \mathrm{~mm}$ and $f_{\mathrm{m}}=50 \mathrm{~Hz}$, the maximum value of $x_{\mathrm{m}}$ can achieve $7 \mathrm{~mm}$.

\subsection{Influence of different $x_{\mathrm{v}}$ on the displacement of main} spool

Fig. 8 shows the maximum value of $x_{\mathrm{m}}$ with different frequency when $x_{\mathrm{v}}$ are $2 \mathrm{~mm}$ and $1.5 \mathrm{~mm}$, respectively. It can be seen from Fig. 8 , the smaller the $x_{v}$, the smaller the maximum value of $x_{\mathrm{m}}$. Figs. 7 and 8 show that the main spool can be controlled through controlling the oil-supply pressure of control system, rotate speed of secondary spool and the axial displacement of spool. Besides, when the oil-supply pressure is $21 \mathrm{MPa}, x_{\mathrm{v}}=2 \mathrm{~mm}$ and $f_{\mathrm{m}}=50 \mathrm{~Hz}$, the maximum displacement of main spool and the maximum flow area can achieve $4 \mathrm{~mm}$ and $440 \mathrm{~mm}^{2}$ with $50 \mathrm{~Hz}$. The maximum displacement of main spool and the maximum flow area when frequency is $100 \mathrm{~Hz}$ are $1 / 2$ of that when frequency is $50 \mathrm{~Hz}$. The maximum displacement of main spool and the maximum flow area when frequency is $200 \mathrm{~Hz}$ are $1 / 4$ of that when frequency is $50 \mathrm{~Hz}$. Among them, when $D_{\mathrm{m}}=44 \mathrm{~mm}$, the maximum displacement of main spool and the maximum flow area are $3.2 \mathrm{~mm}$ and $440 \mathrm{~mm}^{2}$ with $50 \mathrm{~Hz}$. The changing rule of the maximum displacement of main spool and the maximum flow area are the same as the above. Under the same condition, when $D_{\mathrm{m}}=44 \mathrm{~mm}$, the displacement of main spool is smaller, but the total flow area is invariant relative to the main spool that $D_{\mathrm{m}}=35 \mathrm{~mm}$. According to $Q_{\mathrm{mmax}}=C_{\mathrm{d} \pi} D_{\mathrm{m}} x_{\mathrm{m}} \sqrt{\frac{2 p_{\mathrm{s}}}{\rho}}$, when $D_{\mathrm{m}}=35 \mathrm{~mm}$, $x_{\mathrm{m}}=4 \mathrm{~mm}, p_{\mathrm{s}}=10 \mathrm{MPa}$, the maximum flow can achieve 0.041 $\mathrm{m}^{3} / \mathrm{s}$ under no-load condition.

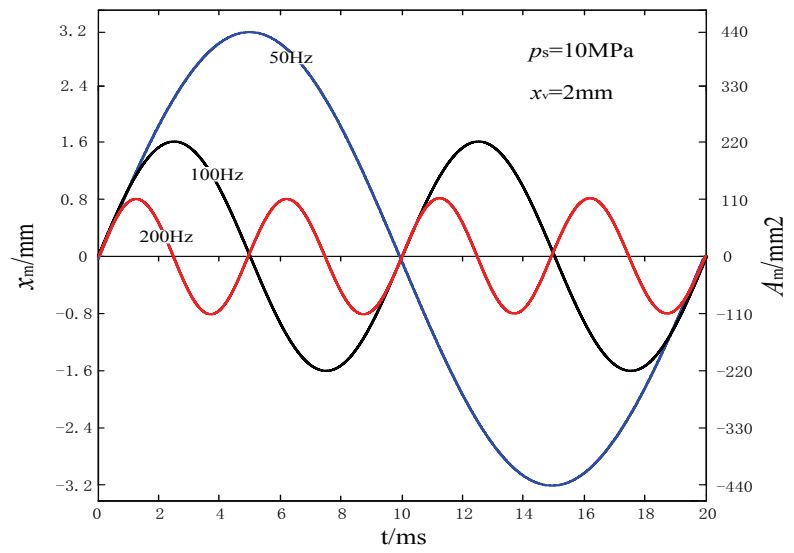

Figure 6 Curves of $\mathrm{x}_{\mathrm{m}}$ and $\mathrm{A}_{\mathrm{m}}$ with different frequency (the main spool $\mathrm{D}_{\mathrm{m}}$ is $44 \mathrm{~mm}$ )

maximum value of $x_{\mathrm{m}}$ can achieve $7 \mathrm{~mm}$.

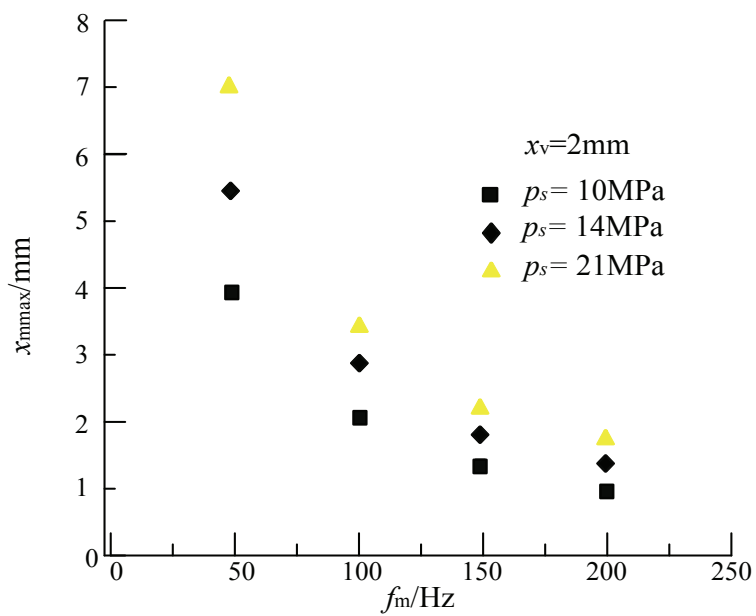

Figure 7 Maximum value of $\mathrm{x}_{\mathrm{m}}$ with different reversing frequency (three oil-supply pressure) 


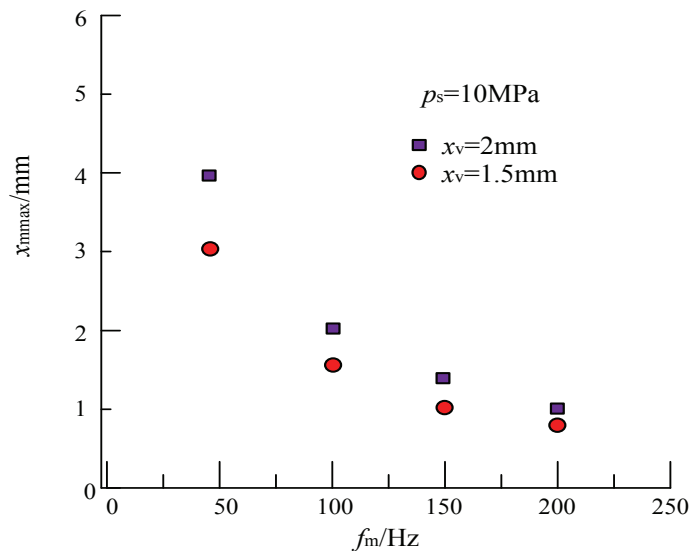

Figure 8 Curves of maximum value of $\mathrm{x}_{\mathrm{m}}$ with different frequency(the axial opening of different secondary valves )

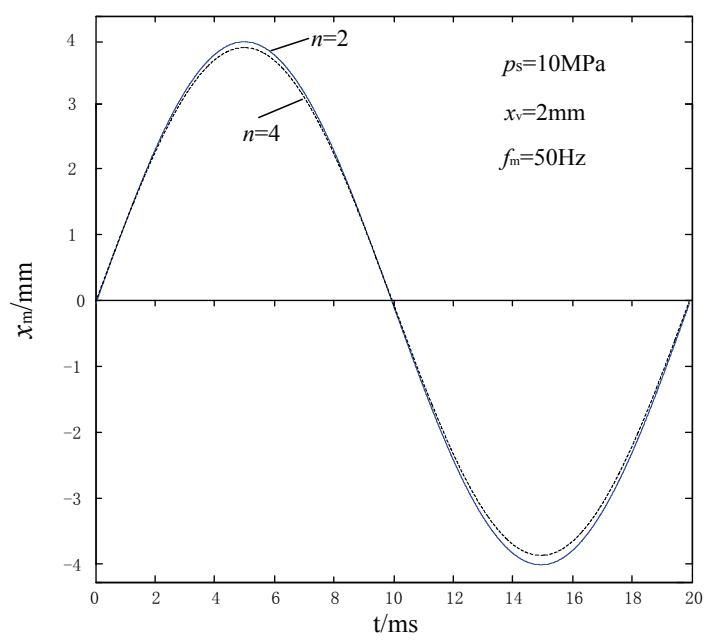

Figure 9 Curves of $x_{m}$ with different $n$

\section{Conclusion}

The paper presents a new two-stage excitation valve used in vibration experiment system and establishes the mathematical models. The characteristic of two-stage excitation valve is obtained by using Matlab/Simulink.

The results show that the displacement of main spool will be smaller with bigger diameter and more secondary valve ports. The maximum displacement of main spool will be smaller with higher reversing frequency, lower oil-supply pressure and smaller axial guide width of valve ports. The new two-stage excitation valve is easy to adjust reversing frequency and flow. The higher frequency can be realized by adding the number of secondary valve ports. The larger flow can be achieved by increasing axial guide width of secondary valve ports and oil supply pressure. The result of this study is of guiding significance for designing the rotary valve for the achievement of higher reversing frequency and larger flow.

Acknowledgments: This work was supported by the Ningbo "Science and Technology Innovation 2025" major
4.4. Influence of different number of secondary valve ports on the displacement of main spool

It can be seen from Fig. 9, when the oil-supply pressure is $10 \mathrm{MPa}$, the reversing frequency of main spool is $50 \mathrm{~Hz}$, $x_{\mathrm{v}}=2 \mathrm{~mm}$, the displacement of two-stage valve main spool with 8 secondary valve ports is slightly smaller than that with 4 secondary valve ports. The total flow conduction areas are same with different number of secondary valve ports shown as Fig.10 in theory. However, the more the number of secondary valve ports, the bigger the local resistance of the single controlling port to the oil, causing the displacement of main spool smaller when other condition are same. According to the structure of valve and the equation $f_{\mathrm{m}}=2 \mathrm{n} f$, we can get that it is easy to realize bigger reversing frequency or high frequency vibration with more secondary valve ports.

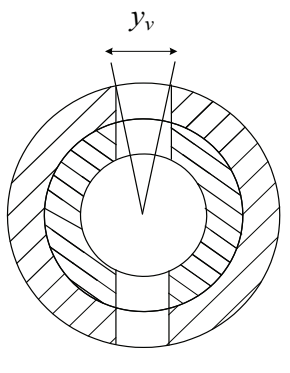

2 ports

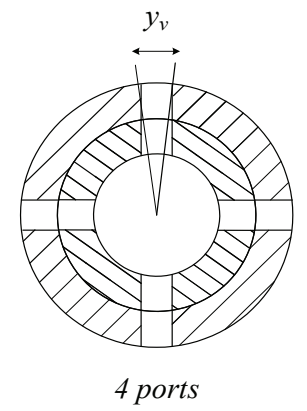

Figure 10 Width of $y_{v}$ with different ports project (202002P2004) , the Natural Science Foundation of Ningbo City of China (2019A610162) and the National Natural Science Foundation of China (51605431).

\section{References}

[1] Li Xiaojun, Li Fangfang, Ji Jinbao, Wang Juke. A new control technology of shaking table based on the jerk. Advanced Engineering Sciences 2018, Volume (3), pp. 64-72.

[2] Xin Yanggui, Dou Baohui, Pei Yang, Liu Chunhu. Application of high frequency electro-hydraulic vibration system. Machine Tool \& Hydraulics 2015, Volume 43(13), pp. 106-107.

[3] Wang Wei. Research on the technology of impact vibration based on four-way rotary valve. Zhejiang University, 2016.

[4] Ivan O, Karem A, Siamak S, Philip, G. Numerical and experimental investigation of the metering characteristic and pressure losses of the rotary tubular spool valve. Flow Measurement and Instrumentation 2020, DOI : 
https: // doi.org/ 10.1016/ j.flowmeasinst. 2019.101679.

[5] Hao Jiangong, Zhang Yaocheng. Study on the properties of a new electrohydraulic exciting system. Journal of Taiyuan University of Technology 2003, Volume 6, pp.706-709.

[6] Lu Juxian, Li Shuli, Jiao Zongxia. A Limited-angle rotating of Electro-Hydraulic Servo-valve. Hydraulics Pneumatics \& Seals 2005, Volume 4, pp.40-42.

[7] Fu Yongling, Song Guobiao. The steady flow force analysis of a new direct drive servo valve. Machine Tool \& Hydraulics 1998, Volume 6, pp.18-20.

[8] Ren Yan, Tang Hesheng, Xiang Jiawei, Experimental and numerical investigations of hydraulic resonance characteristics of a high-frequency excitation system. Mechanical Systems and Signal Processing 2019, Volume 131, pp. 617-632.

[9] Ren Yan, Bai Jiping, Ruan Jian, Design, modeling and experimental validation of a variable resonant electrohydraulic fatigue testing system. IEEE ACCESS 2019, Volume 7, pp.180825-180845.

[10] Ren Yan, Ji Xiancheng, Ruan Jian, Output characteristics of a horizontal type electro-hydraulic excitation system with inertial loading: Modeling and experimentation. Journal of Mechanical Science and Technology 2019,
Volume 33(11), pp. 5157-5167.

[11] Liu Yi, Gong Guofang, Yang Huayong, Han Dong, and Wang He. Regulating Characteristics of New Tamping Device Exciter Controlled by Rotary Valve . IEEE/ASME Transactions on Mechatronics, 2016, Volume 21(1), pp.497-505.

[12] Wang Weirui, Li Xing, Ge Zheng, Shi Haoran. The spool transfering composite hydraulic vibration control valve and its hydraulic system: China, 201410839682.5.[P].2016-06-08.

[13] Cui Jian, Ding Fang, Li Qi Peng. Novel bidirectional rotary proportional actuator for electrohydraulic rotary valves. IEEE Transactions on Magnetics 2007, Volume 43(7), pp.3254-3258.

[14] Liu Yi, Cheng ShaoKe, Gong GuoFang. Structure characteristics of valve port in the rotation-spool-type electro-hydraulic vibrator. Journal of Vibration and Control 2017, Volume 23, pp. 2179-2189.

[15] Liu Yi, Jiafei ZHENG , Song Ruiyin, Xu Qiaoning, Chen Junhua, Huang Fangping. Simple Push-Type Wave Generating Method Using Digital Rotary Valve Control. Chinese Journal of Mechanical Engineering 2020, Volume 33(1), pp. 1-16. 